\title{
Sarcopenia and Postoperative Complications in Gastrointestinal Cancer
}

\author{
Camila Cava Miguel $^{1 *}$, Virgínia Desirée Mendes de Moraes Kliemannn ${ }^{1}$, Camila Brandao Polakowski ${ }^{1}$, \\ Vinícius Basso Preti ${ }^{2}$, Flavio Daniel Saavedra Tomasich ${ }^{2}$ and Vitor Arce Cathcart Ferreira ${ }^{2}$ \\ ${ }^{1}$ Department of Nutrition, Erasto Gaertner Hospital, Brazil \\ ${ }^{2}$ Oncologic surgery, Erasto Gaertner Hospital, Brazil
}

*Corresponding author: Camila Cava Miguel, Department of Nutrition, Erasto Gaertner Hospital, Brazil.

Received Date: January 26, 2019

Published Date: February 21, 2019

\section{Abstract}

Background: Surgical procedures in the treatment of gastrointestinal cancer have an impact on nutritional status. Sarcopenia has been determined as an independent factor for the increase of postoperative complications in elderly patients. cancer

Objective: Correlate the presence of sarcopenia with postoperative complications in elderly patients with gastrointestinal

Methods: Prospective study, including 46 elderly patients undergoing curative and elective surgery of the gastrointestinal tract. Sarcopenia was identified using the criteria of The European Working Group on Sarcopenia in Older People. The nutritional profile of the sample was evaluated by the Patient-Generated Subjective Global Assessment, biochemical parameters of transferrin, albumin and total lymphocyte count and by the Body Mass Index. Statistical analysis was performed using the Statistical Package for Social Sciences ${ }^{\circledR}$ (SPSS) program. The t test, Chi-square, in addition to the ROC curve and the non-linear regression analysis were applied. Statistical significance was considered when $\mathrm{p}<0.05$ with a $95 \%$ confidence interval (CI).

Result: In the sample, 30,4\% (n=14) of the patients were sarcopenic. Sarcopenia was associated with an increase in postoperative complications ( $p=0.003$ ), in addition to an increase in length of hospital stay ( $p=0.042)$. The ROC curve showed area under the curve of 0,807 , and nonlinear regression analysis demonstrated that $80 \%$ of patients with sarcopenia are at higher risk of postoperative complications. Conclusion: Sarcopenia is an independent risk factor for the development of postoperative complications, and it is associated with increased length of hospital stay. The effectiveness of nutritional intervention should be evaluated in this group.

Keywords: Sarcopenia; Nutritional status; Neoplasms

Abbreviations: EWGSOP: The European Working Group on Sarcopenia in Older People; BMI: Body Mass Index; \% WL: Percentage of Weight Loss; ICU: Intensive Care Unit; COPD: Chronic Obstructive Pulmonary Disease; PG-SGA: Patient-Generated Subjective Global Assessment; BIA: Bioelectrical Impedance; SPPB: Short Physical Performance Battery; TLC: Total Lymphocyte Count; UICC: International Union Against Cancer; INCA: National Cancer Institute

\section{Introduction}

The treatment of cancer, especially tumors of the gastrointestinal tract, has surgery as one of the modalities of therapeutic approach. Surgical procedures are performed in these individuals with a curative purpose in about $60 \%$ of the cases, besides helping staging and diagnosis of cancer [1]. Surgeries performed in the gastrointestinal tract are generally large and may influence the nutritional status of the patients resulting in weight loss, increased length of stay and postoperative complications such as sepsis, abdominal abscess, difficulty in wound healing, respiratory and cardiac problems [2]. Approximately $10 \%$ of the world's population is elderly and an increase of this population is estimated for $32 \%$ of the world's elderly by 2050 . Geriatric syndromes, non-communicable chronic diseases, cardiovascular and metabolic diseases, sarcopenia and cancer are more incidental in this population, due to the increase in the risks for their 
development. Due to loss of muscle function and increased of physical dependence, the elderly presents a higher prevalence of sarcopenia $[3,4]$.

Sarcopenia, one of the changes associated with cancer and its treatments and which existence has been identified as an independent risk factor for complications, is characterized by the loss of lean mass and muscle strength [5-9]. The European Working Group on Sarcopenia in Older People (EWGSOP) classified sarcopenia in three stages, according to their severity, as presarcopenia, sarcopenia and severe sarcopenia [10]. Several studies have reported the impact of sarcopenia in oncology and surgical patients and its implications, showing that sarcopenia is an independent factor in increasing hospitalization time, mortality, risk of postoperative complications, and poor quality of life [5-9,11-14]. The identification of the presence of sarcopenia as a risk factor in the preoperative period is essential for the best choice of treatment and determination of the prognosis of surgical patients [2]. The aim was to correlate the presence of sarcopenia with postoperative complications in elderly patients with gastrointestinal cancer.

\section{Materials and Methods}

A prospective, cross-sectional study with a quantitative approach, approved by the Research Ethics Committee of the Erasto Gaertner Hospital, number of opinions 50957315.3.0000.0098. The sample calculation was performed by the Epi Info TM 7.1.3 program, establishing $95 \%$ of confidence and 5\% of error risk, resulting in a population of 44 elderly. The sample was selected by non-probabilistic sampling, for convenience and consecutively in the period of the research. The researchers of the study were previously trained to collect data, so that there was no significant difference in applied methodology.

\section{Patients}

Patients who underwent curative and elective gastrointestinal cancer surgery performed at the Erasto Gaertner Hospital, Curitiba, Paraná, from March to October 2016 were invited to participate in the study. Inclusion criteria were: patients aged 60 years or older; diagnosis of cancer of the esophagus, stomach, colon and rectum. Exclusion criteria were: patients submitted to surgery without curative intuition; presence of edema due to the alteration that may occur in bioelectrical impedance and patients who were not able to perform the proposed tests.

\section{Data collection}

All the data collected were compiled in a digital database (Excel@), containing: surgery performed, sex, age, comorbidities, neoadjuvant treatment (chemotherapy and radiotherapy), disease's staging (T1, T2, T3 and T4), body mass index (BMI), percentage of weight loss ( $\% \mathrm{WL}$ ), postoperative complications (within 30 days after surgery), intensive care unit (ICU) stay, hospital stay and readmission (considered within 30 days after hospital discharge) and results of tests of albumin, transferrin and total lymphocyte count. Other comorbidities were considered: chronic obstructive pulmonary disease (COPD) and smoking. All data were collected from the database of the electronic patient record by the hospital integrated system.

\section{Nutritional assessment}

Weight and height were measured according to Nhanes, 2009 [15], using a platform scale with a capacity of $200 \mathrm{~kg}$, graduated in $50 \mathrm{~g}$ of the brand Welmy W 200/50 A®, containing the anthropometric ruler of the platform scale (W 200/50 A®), measuring from 100 to $202 \mathrm{~cm}$, with a variation of $0,1 \mathrm{~cm}$. The percentage of weight loss (\% WL) was considered as significant or not according to criteria of Blackburn et al, 1977 [16]. BMI was classified for elderly patients according to WHO, 1995 [17] cut-off points. As a subjective evaluation of nutritional status, the Patient-Generated Subjective Global Assessment (PG-SGA), specific for oncologic patients, was applied according to guidelines for cancer patients [18].

\section{Evaluation of sarcopenia}

The presence of sarcopenia was defined according to the criteria of the EWGSOP, which classified them into pre-sarcopenia, sarcopenia and severe sarcopenia. Pre-sarcopenia is defined by the reduction of skeletal muscle mass alone; sarcopenia is characterized by reduction of skeletal muscle mass plus reduction of handgrip strength or reduction of physical performance; severe sarcopenia has a reduction in all three parameters, which are reduced skeletal muscle mass, reduced palmar grip strength and poor physical performance [10]. Bioelectrical impedance (BIA) was used to determine skeletal muscle mass, the handgrip strength to determine muscle strength and the Short Physical Performance Battery (SPPB), to evaluate physical performance [10]. In order to perform the BIA, a fasting of 4 hours, alcohol withdrawal for 8 hours and emptying of the bladder was required, which had been previously instructed to the patients. The device used for the evaluation was the Maltron $\AA$ Bio-Scan 916, a bioimpedance device and body composition analyzer, which provides the values of fat and fat free mass percentage in the body. The equation used by Janssen [19] was an instrument to determine skeletal muscle mass. Therefore, the equation proposed by EWGSOP was used to determine reduced muscle mass [skeletal muscle mass $/$ height $^{2}$ ] and the cut-off point used, from this result, was $8,87 \mathrm{~kg} / \mathrm{m}^{2}$ for men and $6,42 \mathrm{~kg} / \mathrm{m}^{2}$ for women $[10,20-22]$. The handgrip strength test was performed through the use of a hand-held dynamometer Smedley type, brand Jamar®, model 5032P, with a capacity of $100 \mathrm{~kg}$. The force was applied to the device 3 consecutive times with the dominant hand of the patient. Three measurements were performed, and the final value obtained was the average between the three measurements. The reference values for determining reduced handgrip strength are in accordance with the EWGSOP [10,23-25]. The physical performance evaluation was through the SPPB, performed according to guidelines and criteria of Nakano [26], with a validated instrument for the brazilian population. Balance, sit and stand from the chair tests were performed in addition to the 3-meter walking test. Patients with a final score of 0 to 3 were considered to have very poor performance, from 4 to 6 with poor performance, from 7 to 9 with moderate performance and from 10 to 12 with good performance. Patients with scores equal to or less than 6 were considered to have poor performance when considering the assessment of sarcopenia. 


\section{Laboratory tests}

Laboratory tests of albumin, total lymphocyte count (TLC) and transferrin were collected within 24 hours prior to surgery. The reference values considered for the tests, identifying the patient with some degree of malnutrition or protein deficiency, were previously defined in the literature [27-29].

\section{Postoperative complications}

Complications within 30 days after the surgical procedure were considered: surgical wound infection, urinary tract infection, pneumonia, sepsis, anastomosis dehiscence and fistula.

\section{Tumor staging}

The tumor staging was performed by the TNM classification of the International Union Against Cancer (UICC), the seventh edition, published in 2010 and translated into Portuguese in 2012 by the National Cancer Institute (INCA). The classification includes the degree of tumor invasion (T), the number of metastatic lymph nodes $(\mathrm{N})$ and the presence of metastasis (M) [30].

\section{Bowel preparation}

All patients received prophylactic antibiotics for 24 hours. The antimicrobial regimen was the combination of metronidazole $(500$ mg 8/8 hours for 24 hours) and ceftriaxone (2 grams in a single dose) for all operations, intravenously, beginning at anesthesia induction. Antibiotic therapy was maintained for more than 24 hours by decision of the responsible surgeon, and the total length of antibiotics usage was calculated for each patient. Prophylactic low molecular weight heparin (Clexane ${ }^{\circledR}$ ) was use subcutaneously in all patients at anesthesia induction.

\section{Statistical analysis}

$\mathrm{T}$ and Chi-square tests were performed. The Chi-square test was performed to associate categorical variables of population characteristics, nutritional status and complications. The ROC curve was used to determine the specificity and sensitivity of the relationship between sarcopenia and complications. In addition, non-linear regression analysis was performed to evaluate nondependent variables (sarcopenia e complication). Statistical analysis was performed by the Statistical Package for the Social Sciences ${ }^{\circledR}$ (SPSS) program, version 19.0 for Windows (SPSS Inc, Chicago, IL, USA). Statistical significance was considered when $\mathrm{p}$ $<0.05$ in a $95 \%$ confidence interval (CI).

\section{Result and Discussion}

From March to October 2016, 67 patients were evaluated. Of these, 21 patients were excluded from the study due to absence of malignancy, palliative surgery, absence of laboratory tests, water change and impossibility of performing BIA. Forty-six $(n=46)$ patients were included in the study. The average length of stay in the ICU was 1,37 days and the average length of hospital stay was 5,79 days. Only $6,5 \%(n=3)$ of the patients were readmitted within a period of up to 30 days. In $71,7 \%$ of the population there was no need for adjuvant treatment (Table 1). The sarcopenic patients were identified in $30,4 \%(n=14)$ of the sample, distributed in $13 \%(n=6)$ pre-sarcopenics, $15,2 \%(n=7)$ sarcopenics and $2,2 \%(n=1)$ severe sarcopenic. Analyzing the characteristics of the nutritional status of the population (Table 2), it can be observed that BMI classified 15,2\% of the study population as underweight (mean BMI of $27,37 \mathrm{~kg} / \mathrm{m}^{2}$ ). The PG-SGA, specific for cancer patients, classified $56,5 \%$ of the patients with some degree of malnutrition. The difference between the underweight and malnutrition classification of BMI and PGSGA was also found in Cardoso's study in 2012 [31] (21,8\% BMI x $58,4 \%$ PG-SGA), which evaluated the nutritional status of oncologic patients. The classification of nutritional status by BMI for cancer patients is limited, since the index does not consider symptoms that may limit food intake, weight loss and physical examination, and may underestimate their nutritional status [32]. However, the PG-SGA is a specific and sensitive instrument for the determination of the nutritional status of cancer patients. It is considered a gold standard tool for the evaluation of these patients, and its use can be given as a prognostic indicator, identifying patients who can benefit of previous nutritional interventions [33-37].

Table 1: Clinical and demographic characteristics of the sample.

\begin{tabular}{|c|c|c|}
\hline Variable & & \\
\hline Study population (n) & 46 & \\
\hline Age, median (min - max) & $71,78(61-90)$ & \\
\hline Sex & $\%$ & $\mathbf{n}$ \\
\hline Female & 34,8 & 16 \\
\hline Male & 65,2 & 30 \\
\hline \multicolumn{3}{|l|}{ Surgeries } \\
\hline Abdominal Retosigmoidectomy & 8,7 & 4 \\
\hline $\begin{array}{l}\text { Retosigmoidectomy with } \\
\text { colostomy }\end{array}$ & 23,9 & 11 \\
\hline $\begin{array}{l}\text { Retosigmoidectomy with } \\
\text { ileostomy }\end{array}$ & 2,2 & 1 \\
\hline Ileocolectomy & 13 & 6 \\
\hline Colectomy & 13 & 6 \\
\hline Abdominoperineal excision & 10,9 & 5 \\
\hline Partial gastrectomy & 21,7 & 10 \\
\hline Esophagectomy & 4,3 & 2 \\
\hline Abdominal sigmoidectomy & 2,2 & 1 \\
\hline \multicolumn{3}{|l|}{ Staging } \\
\hline $\mathrm{T} 1$ & 19,6 & 9 \\
\hline $\mathrm{T} 2$ & 15,2 & 7 \\
\hline $\mathrm{T} 3$ & 54,3 & 25 \\
\hline $\mathrm{T} 4$ & 10,9 & 5 \\
\hline \multicolumn{3}{|l|}{ Comorbidities } \\
\hline None & 34,7 & 16 \\
\hline Diabetes & 17,4 & 8 \\
\hline Arterial hypertension & 60,8 & 28 \\
\hline Others & 15,2 & 7 \\
\hline \multicolumn{3}{|l|}{ Neoadjuvant treatment } \\
\hline None & 71,7 & 33 \\
\hline Chemotherapy & 4,3 & 2 \\
\hline Radiotherapy & 2,2 & 1 \\
\hline Chemotherapy + Radiotherapy & 21,7 & 10 \\
\hline
\end{tabular}

T1, degree of tumor invasion 1; T2, degree of tumor invasion 2; T3, degree of tumor invasion 3; T4, degree of tumor invasion 4. 
Table 2: Characteristics of the nutritional status of the sample.

\begin{tabular}{|c|c|c|}
\hline Variable & $\%$ & $\mathrm{n}$ \\
\hline \multicolumn{3}{|l|}{ BMI* } \\
\hline Underweight & 15,2 & 7 \\
\hline Eutrophy & 21,7 & 10 \\
\hline Overweight & 63 & 29 \\
\hline \multicolumn{3}{|l|}{ Weight loss } \\
\hline Significant & 32,6 & 15 \\
\hline Not significant & 67,4 & 31 \\
\hline \multicolumn{3}{|l|}{ PG-SGA* } \\
\hline Well nourished & 43,5 & 20 \\
\hline Moderately malnourished & 32,6 & 15 \\
\hline Severely malnourished & 23,9 & 11 \\
\hline \multicolumn{3}{|l|}{ Albumin } \\
\hline Adequate & 54,3 & 25 \\
\hline Mild malnutrition & 28,3 & 13 \\
\hline Moderate malnutrition & 17,4 & 8 \\
\hline \multicolumn{3}{|l|}{ Total Lymphocyte Count } \\
\hline Adequate & 32,6 & 15 \\
\hline Mild malnutrition & 39,1 & 18 \\
\hline Moderate malnutrition & 15,2 & 7 \\
\hline Severe malnutrition & 13 & 6 \\
\hline \multicolumn{3}{|l|}{ Transferrin } \\
\hline Normal & 91,3 & 42 \\
\hline Moderate protein deficiency & 4,3 & 2 \\
\hline Severe protein deficiency & 4,3 & 2 \\
\hline \multicolumn{3}{|l|}{ Handgrip strength } \\
\hline Adequate & 30,4 & 14 \\
\hline Inadequate & 69,6 & 32 \\
\hline \multicolumn{3}{|l|}{ Skeletal muscle mass (BIA*) } \\
\hline Adequate & 69,6 & 32 \\
\hline Reduced & 30,4 & 14 \\
\hline \multicolumn{3}{|l|}{ Sarcopenia } \\
\hline Pre-sarcopenia & 13 & 6 \\
\hline Sarcopenia & 15,2 & 7 \\
\hline Severe sarcopenia & 2,2 & 1 \\
\hline
\end{tabular}

*BMI: Body Mass Index; PG-SGA: Patient-Generated Subjective Global Assessment; BIA: Bioelectrical impedance.

The handgrip strength demonstrated that $69,6 \%$ of the patients in the sample had reduced muscle strength (Table 2). According to the EWGSOP criteria, the first factor to identify the presence of sarcopenia is reduced muscle mass, identified in this study through BIA. However, the loss of strength and muscle mass are not always proportional, mainly due to neuronal activities in the elderly, which reduces functionality, causing a more pronounced loss of muscle strength. Handgrip strength is a predictor of clinical outcome and correlates with complications and functional impairment of patients [10,38,39]. The study by Klidjian [40], performed with a sample of 225 patients submitted to abdominal surgery, with a pre-operative handgrip strength, identified a correlation between reduced grip strength and postoperative complications. Such correlation was not determined in this study; however, handgrip strength is a good indicator of clinical and daily use for the evaluation of muscle strength decline. In this sample, 30,4\% $(n=14)$ of patients presented general complication. Sarcopenia was an independent predictor of complications $(p=0,003)$ (Table 3). There was no statistically significant correlation with other nutritional assessment methods, biochemical tests, disease staging, comorbidities or adjuvant treatment, in other words, none of the other variables were associated with a higher occurrence of complications $(p>0,05)$. Several studies have detected sarcopenia as a predictor of postoperative complications [11,14,41-44]. In the present study, $30,4 \%$ of the patients were identified as sarcopenic. Through the analysis of the ROC curve it was possible to observe that sarcopenia was a sensitive and specific predictor of postoperative complications, with an area above the curve of 0,807 (95\% CI) (Figure 1). Non-linear regression analysis demonstrated that $80 \%$ of patients with sarcopenia are at higher risk of postoperative complications (Figure 1).

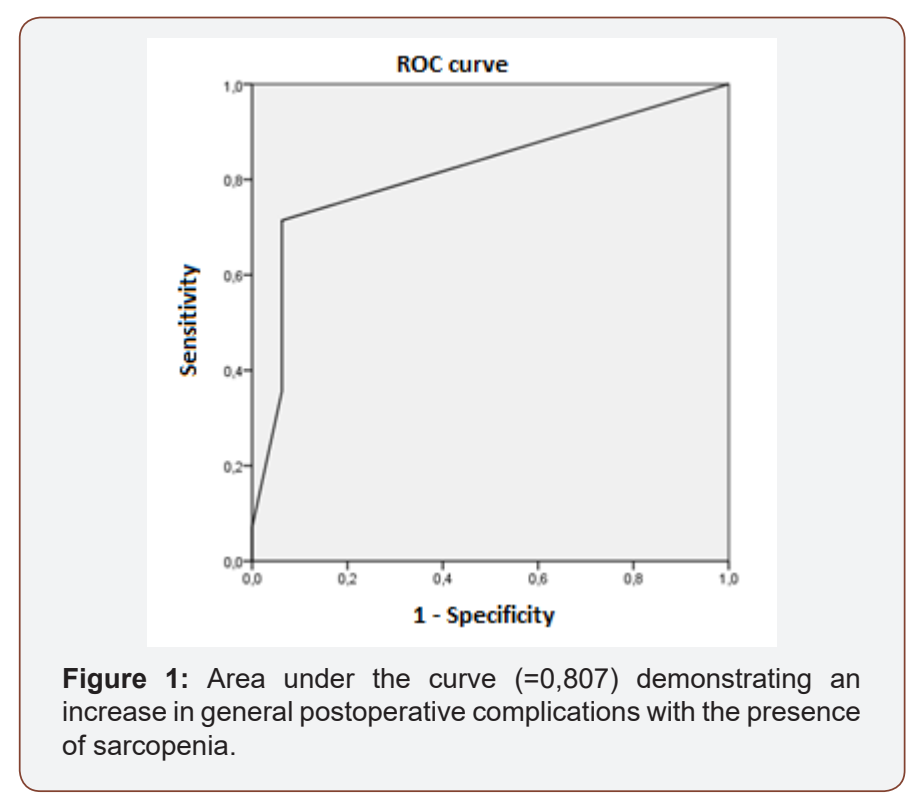

Table 3: Nutritional status and general postoperative complications.

\begin{tabular}{|c|c|c|}
\hline Variable & $\begin{array}{c}\text { General complication } \\
(\mathrm{n}=14)\end{array}$ & P value \\
\hline BMI* $(\mathbf{\%}, \mathbf{n})$ & & 0,991 \\
\hline Underweight & $4,3(2)$ & \\
\hline Eutrophy & $6,5(3)$ & \\
\hline Overweight & $19,6(9)$ & \\
\hline Weight loss & & 0,096 \\
\hline Significant & $15,2(7)$ & \\
\hline Not significant & $15,2(7)$ & \\
\hline PG-SGA* & & 0,562 \\
\hline Well nourished & $15,2(7)$ & \\
\hline Moderately malnourished & $6,5(3)$ & \\
\hline Severely malnourished & $8,7(4)$ & \\
\hline Albumin & & \\
\hline Adequate & $13(6)$ & \\
\hline Mild malnutrition & $13(6)$ & \\
\hline Moderate malnutrition & $4,3(2)$ & \\
\hline
\end{tabular}




\begin{tabular}{|c|c|c|}
\hline Total Lymphocyte Count & & 0,761 \\
\hline Adequate & $10,9(5)$ & \\
\hline Mild malnutrition & $10,9(5)$ & \\
\hline Moderate malnutrition & $6,5(3)$ & \\
\hline Severe malnutrition & $2,2(1)$ & \\
\hline Transferrin & & 0,673 \\
\hline Normal & $26,1(12)$ & \\
\hline Moderate protein deficiency & $2,2(1)$ & \\
\hline Severe protein deficiency & $2,2(1)$ & \\
\hline Handgrip strength & & 0,05 \\
\hline Adequate & $15,2(7)$ & \\
\hline Inadequate & $15,2(7)$ & \\
\hline \multicolumn{3}{|l|}{ Comorbidities } \\
\hline None & -2 & 0,054 \\
\hline Diabetes & -3 & 0,633 \\
\hline Arterial hypertension & -11 & 0,104 \\
\hline Others & -1 & 0,539 \\
\hline Staging & & 0,488 \\
\hline $\mathrm{T} 1$ & $4,3(2)$ & \\
\hline $\mathrm{T} 2$ & $4,3(2)$ & \\
\hline T3 & $15,2(7)$ & \\
\hline $\mathrm{T} 4$ & $6,5(3)$ & \\
\hline Neoadjuvant treatment & & 0,367 \\
\hline None & $21,7(10)$ & \\
\hline Chemotherapy & $2,2(1)$ & \\
\hline Radiotherapy & $2,2(1)$ & \\
\hline Chemotherapy + Radiotherapy & $4,3(2)$ & \\
\hline Sarcopenia & $10,8(5)$ & 0,003 \\
\hline
\end{tabular}

*BMI: Body Mass Index; PG-SGA: Patient-Generated Subjective Global Assessment; BIA: Bioelectrical impedance; T1: degree of tumor invasion 1; T2: degree of tumor invasion 2; T3: degree of tumor invasion 3; T4: degree of tumor invasion 4.

Huang [11] demonstrated increased postoperative complications with increasing degree of sarcopenia in patients with gastric cancer, and their sample presented $37,4 \%$ of patients with some degree of sarcopenia. Zhuang [14] associated the presence of sarcopenia with a higher occurrence of severe complications in patients with gastric cancer, and $41,5 \%$ of the sample were sarcopenic. Similarly, analyzed by Reisinger [43], in a sample of patients with colorectal cancer, $47.7 \%$ were identified as sarcopenic, and functional impairment was associated with an increase in postoperative complications. Sharma [45] identified $29 \%$ of sarcopenic patients in their sample and, when submitted to nephrectomy for metastatic renal cell carcinoma, sarcopenia increased length of hospital stays. The presence of sarcopenia was also associated with an increase in length of stay in the present study $(p=0,042)$ (Table 4), since the greater the occurrence of complications, consequently the longer the hospitalization time. The presence of sarcopenia was not correlated with disease staging, comorbidities, length of stay in the ICU $(p=0,94)$ and treatment with neoadjuvant chemotherapy or radiotherapy $(p>0,05)$. Among the sarcopenic patients, $71,4 \%(n=10)$ were classified with some degree of malnutrition by PG-SGA, whereas BMI classified 28,5\% of these patients with underweight. Regarding the sample deaths, only one of the three patients who died were sarcopenic, therefore, there was no correlation between sarcopenia and mortality ( $>00,05)$ (Table 4).

Table 4: Correlation of sarcopenia and the sample profile.

\begin{tabular}{|c|c|c|c|}
\hline Variable & Sarcopenic (n) & $\begin{array}{c}\text { Not sarcopenic } \\
\text { (n) }\end{array}$ & $\begin{array}{c}\text { P } \\
\text { value }\end{array}$ \\
\hline Staging & & & 0,198 \\
\hline T1 & 2 & 7 & \\
\hline T2 & 3 & 4 & \\
\hline T3 & 6 & 19 & \\
\hline T4 & 3 & 2 & \\
\hline Comorbidities & & & \\
\hline None & 3 & 13 & 0,438 \\
\hline Diabetes & 4 & 4 & 0,119 \\
\hline Arterial hypertension & 10 & 18 & 0,414 \\
\hline Others & 1 & 1 & 0,786 \\
\hline Neoadjuvant treatment & & & 0,615 \\
\hline None & 11 & 22 & \\
\hline Chemotherapy & 1 & 1 & \\
\hline Radiotherapy & 1 & 0 & \\
\hline Chemotherapy + & 1 & 9 & \\
\hline Radiotherapy & & & 0,042 \\
\hline Length of stay & & & \\
\hline More than 7 days & 6 & 4 & \\
\hline Less than 7 days & 8 & 28 & \\
\hline
\end{tabular}

T1, degree of tumor invasion 1; T2, degree of tumor invasion 2; T3, degree of tumor invasion 3; T4, degree of tumor invasion 4 .

Cancer generates metabolic and systemic changes, leading to loss of muscle mass, one of the factors to identify the presence of sarcopenia. In addition, the tumor cell exacerbates protein catabolism, accentuating the loss of muscle mass. Reduced muscle mass is identified in about $50 \%$ of preoperative patients [2], and this loss makes the patients more likely to develop complications. In addition to oncologic disease, age is also a predictive factor of sarcopenia [12]. The most recent studies elucidate the effects of sarcopenia on postoperative complications. However, there is little literature available to evaluate complications in the presence of nutritional intervention in the preoperative period of sarcopenic patients. Fukuda [12] when evaluating elderly patients with gastric neoplasia identified a low caloric and protein intake in sarcopenic patients prior to surgical treatment, which increased the incidence of postoperative complications. Later, Yamamoto [46] demonstrated that nutritional and physical intervention in these patients had the potential to increase protein and caloric intake, reduce the incidence of sarcopenia, and improve the postoperative clinical course of patients with gastric cancer. Sarcopenic patients should receive adequate nutritional guidance in the preoperative period, aiming to reduce symptoms caused by the underlying disease and to improve the protein and caloric supply. Therefore, these patients need to be properly identified before the surgical procedure. Nutritional status can be assessed through PG-SGA 
and the intervention should be individual, according to the caloric requirement of each patient, considering limitations such as gastrointestinal symptoms [46]. The instruments used in this study to identify the presence of sarcopenia are low cost and can be routinely used as a preoperative nutritional assessment method, especially handgrip strength and BIA. In this way, it is possible to identify patients who are candidates for nutritional counseling. A randomized clinical trial should be developed with the elderly population with sarcopenia and with tumors of esophagus, stomach, colon and rectum, aiming to evaluate nutritional interference in the hospitalization time, reduction of sarcopenia and in the presence of postoperative complications.

\section{Conclusion}

Sarcopenia is an independent risk factor for the development of postoperative complications and is also associated with an increased length of hospital stay in elderly and oncologic patients undergoing gastrointestinal surgery. Studies with intervention groups are necessary to determine the efficacy of preoperative nutritional intervention in sarcopenic patients and to evaluate the response of postoperative complications.

\section{Acknowledgment}

To the Erasto Gaertner Hospital for the space to carry out the research. To the nutrition team of the institution for the help and shared knowledge during this period of preparation of the study.

\section{Conflict of Interest}

None.

\section{References}

1. Costa P, Leite RCBO (2009) Estratégias de Enfrentamento Utilizadas pelos Pacientes Oncológicos Submetidos a Cirurgias Mutiladoras. Rev Bras de Cancerologia 55(4): 355-364.

2. Oliveira LB, Didonet MT, Guimarães NM, Rocha Junior PB (2011) Variables related to hospitalization and postoperative complications of patients undergoing gastrointestinal surgery. Comun. Ciênc. Saúde 21(4): 319-330.

3. De Freitas AF, Prado MA, Cação JC, Beretta D, Albertini S (2015) Sarcopenia e Estado Nutricional De Idosos: Uma Revisão Da Literatura. Arquivos de Ciências da Saúde 22(1): 9-13

4. Nascimento CM, Ribeiro AQ Cotta RMM, Acurcio FA, Peixoto SV, et al. (2011) Nutritional status and associated factors among the elderly in Viçosa, Minas Gerais State, Brazil. Cadernos de Saúde Pública 27(12): 2409-2418.

5. Lieffers JR, Bathe OF, Fassbender K, Winget M, Baracos VE (2012) Sarcopenia is associated with postoperative infection and delayed recovery from colorectal cancer resection surgery. Br J Cancer 107(6): 931-936.

6. Prado CM, Lieffers JR, McCargar LJ, Reiman T, Sawyer MB, et al. (2008) Prevalence and clinical implications of sarcopenic obesity in patients with solid tumours of the respiratory and gastrointestinal tracts: a population-based study. Lancet Oncol 9(7): 629-635.

7. Valero V, Amini N, Spolverato G, Weiss MJ, Hirose K, et al. (2015) Sarcopenia Adversely Impacts Postoperative Complications Following Resection or Transplantation in Patients with Primary Liver Tumors. J Gastrointest Surg 19(2): 272-281.

8. Joglekar S, Asghar A, Mott SL, Johnson BE, Button AM, et al. (2015) Sarcopenia is an independent predictor of complications following pancreatectomy for adenocarcinoma. J. Surg. Oncol 111(6): 771-775.
9. Sabel MS, Lee J, Cai S, Englesbe MJ, Holcombe S, et al. (2011) Sarcopenia as a prognostic factor among patients with stage III melanoma. Ann Surg Oncol 18(13): 3579-3585.

10. Cruz-Jentoft AJ, Baeyens JP, Bauer JM, Boirie Y, Cederholm T, et al. (2010) Sarcopenia: European consensus on definition and diagnosis Report of the European Working Group on Sarcopenia in Older People. Age and ageing 39(4): 412-423.

11. Huang DD, Zhou CJ, Wang SL, Mao ST, Zhou XY, et al. (2017) Impact of different sarcopenia stages on the postoperative outcomes after radical gastrectomy for gastric cancer. Surgery 161(3): 680-693.

12. Fukuda Y, Yamamoto K, Hirao M, Nishikawa K, Nagatsuma Y, et al. (2016) Sarcopenia is associated with severe postoperative complications in elderly gastric cancer patients undergoing gastrectomy. Gastric Cancer 19(3): 986-993.

13. Nishida Y, Kato Y, Kudo M, Aizawa H, Okubo S, et al. (2016) Preoperative sarcopenia strongly influences the risk of postoperative pancreatic fistula formation after pancreaticoduodenectomy. J Gastrointest Surg 20(9): 1586-1594.

14. Zhuang CL, Huang DD, Pang WY, Zhou CJ, Wang SL, et al. (2016) Sarcopenia is an independent predictor of severe postoperative complications and long-term survival after radical gastrectomy for gastric cancer: analysis from a large-scale cohort. Medicine 95(13): e3164.

15. Nhanes (2007) National Health and Nutrition Examination Survey. Anthropometry Procedures Manual.

16. Blackburn GL, Bistrian BR, Maini BS, Schlamm HT, Smith MF (1977) Nutritional and metabolic assessment of the hospitalized patient. JPEN 1(1): 11-22.

17. WHO: World Health Organization (1995) Expert Committee on Physical Status: the Use and Interpretation of Anthropometry. Geneva.

18. INCA. Instituto Nacional de Câncer (Brazil) (2011) Consenso Nacional de Nutrição Oncológica, v. 2 / Instituto Nacional de Câncer. Rio de Janeiro: INCA.

19. Janssen I, Heymsfield SB, Baumgartner RN, Ross R (2000) Estimation of skeletal muscle mass by bioelectrical impedance analysis. J Appl Physiol 89(2): 465-471.

20. Eickemberg M, Sampaio LR, Oliveira CC, Roriz AKC (2011) Bioelectric impedance analysis and its use for nutritional assessments. Rev. nutr 24(6): 873-882.

21. ABN (2009) Associação Brasileira de Nutrologia. Sociedade Brasileira de Nutrição Parenteral e Enteral. Utilização da Bioimpedância para Avaliação da Massa Corpórea. Projeto Diretrizes.

22. Kyle UG, Bosaeus I, De Lorenzo AD, Deurenberg P, Elia M, et al. (2004) Bioelectrical impedance analysis-part I: review of principles and methods. Clinical nutrition 23(5): 1226-1243.

23. Martin FG, Nebuloni CC, Najas MS (2012) Correlation between nutritional status and handgrip strength in the elderly. Rev. bras. geriatr. Gerontol 15(3): 493-504.

24. Novaes RD, Miranda ASD, Silva J0, Tavares BVF, Dourado VZ (2009) Reference equations for predicting of handgrip strength in brazilian middle-aged and elderly subjects. Fisioterapia e Pesquisa 16(3): 217-22.

25. Budziareck MB, Duarte RRP, Barbosa-Silva MCG (2008) Reference values and determinants for handgrip strength in healthy subjects. Clinical Nutrition 27(3): 357-362.

26. Nakano MM (2007) Brazilian version of the Short Physical Performance Battery - SPPB: cross-cultural adaptation and reliability study [Dissertation]. Campinas: Faculdade de Educação da Universidade Estadual de Campinas.

27. Martins C (2008) Assessment of nutritional status and diagnosis. V 1 Curitiba: NutroClínica, xv, pp.485.

28. Vannucchi H, Unamuno MRDL, Marchini JS (1996) Avaliação do Estado Nutricional. Medicina (Ribeirão Preto. Online) 29(1): 5-18. 
29. Guerra LT (2008) Transferrina e pré-albumina séricas como marcadoras da resposta do suporte nutricional em pacientes com câncer de esôfago (Dissertation). Universidade Federal do Rio Grande do Sul.

30. INCA. TNM (2012): Malignant Tumors Classification/National Cancer Institute José Alencar Gomes da Silva. General Coordination for Prevention and Surveillance. 7a. ed -Rio de Janeiro: Inca xxv: pp325.

31. Brito LF, Silva LS, Fernandes DD, Pires RA, Nogueira ADR, et al. (2012) Nutritional Profile of Cancer Patients Assisted by the House of Support for Cancer Patients from the Southwest of Bahia. Revista Brasileira de Cancerologia 58(2): 163-171.

32. Tartari RF, Busnello FM, Nunes CHA (2010) Nutritional Profile of Patients Submitted to Chemotherapy in a Tertiary Outpatient Clinic. Revista Brasileira de Cancerologia 56(1): 43-50.

33. Pañella L, Jara M, Cornejo M, Lastra X, Contreras MG, et al. (2014) Nutritional status and postoperative complications in patients with digestive cancer. Rev. méd. Chile 142(11): 1398-1406.

34. Leuenberger M, Kurmann S, Stanga Z (2010) Nutritional screening tools in daily clinical practice: the focus on cancer. Support Care Cancer 18(2): 17-27.

35. Dos Santos ALB, Marinho RC, Lima PNM, Fortes RC (2012) Patientgenerated subjective nutritional assessment versus other methods of evaluation of nutritional status in oncological patients. Nutrição Clínica 27(4): 243-249.

36. Bauer J, Capra S, Ferguson M (2002) Use of the scored Patient-Generated Subjective Global Assessment (PG-SGA) as a nutrition assessment tool in patients with cancer. European Journal of Clinical Nutrition 56: 779-785.

37. Dock-Nascimento DB, Aguilar-Nascimento JE, Costa HCBAL, Vale VH, Gava MM (2006) Precisão de métodos de estimativa do peso e altura na avaliação do estado nutricional de pacientes com câncer. Rev Bras Nutr Clin 21(2): 111-116.

38. Eichinger FLF, Soares AV, Júnior JMC, Maldaner GA, Domenech SC, et al. (2015) Força de preensão palmar e sua relação com parâmetros antropométricos/Handgrip strength and its relation with anthropometric parameters. Cadernos de Terapia Ocupacional da UFSCar 23(3).

39. Mendes J, Azevedo A, Amaral TF (2013) Força de preensão da mão: quantificação, determinantes e utilidade clínica. Arquivos de Medicina 27(3): 115-120.

40. Klidjian AM, Foster KJ, Kammerling RM, Cooper A, Karran SJ (1980) Relation of anthropometric and dynamometric variables to serious postoperative complications. Br Med J 281(6245): 899-901.

41. Huang DD, Wang SL, Zhuang CL, Zheng BS, Lu JX, et al. (2015) Sarcopenia, as defined by low muscle mass, strength and physical performance, predicts complications after surgery for colorectal cancer. Colorectal Dis 17(11): 0256-0264.

42. Boer BC, de Graaff F, Brusse-Keizer M, Bouman DE, Slump CH, et al. (2016) Skeletal muscle mass and quality as risk factors for postoperative outcome after open colon resection for cancer. International journal of colorectal disease 31(6): 1117-1124.

43. Reisinger KW, van Vugt JL, Tegels JJ, Snijders C, Hulsewé KW, et al. (2015) Functional compromise reflected by sarcopenia, frailty, and nutritional depletion predicts adverse postoperative outcome after colorectal cancer surgery. Annals of surgery 261(2): 345-352.

44. Mei KL, Batsis JA, Mills JB, Holubar SD (2016) Sarcopenia and sarcopenic obesity: do they predict inferior oncologic outcomes after gastrointestinal cancer surgery? Perioperative Medicine 5(1): 30.

45. Sharma P, Zargar-Shoshtari K, Caracciolo JT, Fishman M, Poch MA, et al. (2015) Sarcopenia as a predictor of overall survival after cytoreductive nephrectomy for metastatic renal cell carcinoma. In: Urol Oncol: Seminars and Original Investigations. Elsevier 33(8): 339.e17-23.

46. Yamamoto K, Nagatsuma Y, Fukuda Y, Hirao M, Nishikawa K, et al. (2016) Effectiveness of a preoperative exercise and nutritional support program for elderly sarcopenic patients with gastric cancer. Gastric Cancer pp. $1-6$. 